\title{
Site-specific prolapse surgery. I. Reliability and durability of native tissue paravaginal repair
}

\author{
Richard I. Reid $\cdot$ Hui You $\cdot$ Kehui Luo
}

Received: 22 April 2009 /Accepted: 8 November 2010 /Published online: 11 January 2011

(C) The Author(s) 2011. This article is published with open access at Springerlink.com

\begin{abstract}
Introduction and hypothesis This study aims to compare native tissue abdominal and vaginal paravaginal repair, and to investigate whether surgical outcome was independent of operative route.

Methods Retrospective comparison of 111 displacement cysto-urethrocoeles, repaired between 1997 and 2007. Treatment was by surgeon assignment, 52 women having abdominal (APVR) and 59 vaginal paravaginal repairs. Main outcome measures were same-site prolapse recurrence, time to failure and surgical complications. Initial reliability was evaluated by chi-square test, 10-year durability by Kaplan-Meier survival analysis and Cox proportional hazards model.

Results When examined in the Cox proportional hazards model, anatomic results of APVR were more durable than a mechanically analogous transvaginal operation done $[95 \%$ $\mathrm{CI}=1.029-2.708$ ( $p$ value=0.038)]. Kaplan-Meier curves plateaued within 38 months. Symptom resolution was broadly equivalent. Surgical complication rate was 3.6\%. Conclusions Site-specific re-suture of torn native tissue has genuine curative potential. Most of the long-term success
\end{abstract}

Part II of this article can be found at DOI 10.1007/s00192-010-1346-3.

\section{R. I. Reid}

School of Rural Medicine, University of New England,

Armidale, Australia

H. You $\cdot$ K. Luo

Statistics Department, Macquarie University,

Sydney, Australia

\section{R. I. Reid $(\bowtie)$}

Specialist Medical Centre,

Suite \#4, 235 New South Head Rd,

Edgecliff, NSW 2027, Australia

e-mail: richard_reid@dbgyn.com was attributable to site-specific repair, rather than nonspecific scar formation.

Keywords Abdominal and vaginal paravaginal repair. Biocompatible materials . Connective tissue pathology . Cystocoele aetiology Reconstructive surgical procedures . Surgical complications
Abbreviations
ATFP Arcus tendineus fascia pelvis
VPVR Vaginal paravaginal repair
APVR Abdominal paravaginal repair

\section{Introduction}

The anterior vaginal wall is a fascial diaphragm, tautly strung between the pericervical ring above and the urogenital diaphragm below, and attached laterally to the two fascial white lines [1-3]. As such, the pubocervical fascia functions like a trampoline, providing all direction support to the proximal urethra and bladder base. It has traditionally been believed that the central fascia of this suspensory hammock attenuates after childbirth, thus forming the bulge of a cystocele or cysto-urethrocele. In reality, healthy fascia is like canvas. It does not stretch, but it will tear at pre-determined points [4]. As a matter of engineering principle, these pre-determined points of weakness lie where the lines of force concentrate: namely along the peripheral margins, not within the central hammock. The distal attachment to the pubic ramus is particularly strong; moreover, the lower vagina is less exposed to obstetric trauma because extension of the foetal head focuses force vectors posteriorly. In contrast, as the 
presenting part overcomes soft tissue resistance in the mid-pelvis during engagement and rotatory descent, the superior and lateral margins of this suspensory hammock are at substantial risk of direct injury $[5,6]$. Fascial avulsion at the superior and lateral trapezoid transforms the diaphragm from a trampoline to a trapdoor. Valsalva pressure will subsequently create a cystocele.

In summary, the formation of a displacement cystocele has three elements: an apical defect, a lateral defect on at least one side and a fulcrum about which rotation can occur. This fulcrum can be located at either the urogenital diaphragm (creating diffuse descent of the entire anterior vaginal wall and a tendency to stress urinary incontinence), or at the vesical neck (creating a high cystocele and a tendency to voiding dysfunction). To be biomechanically appropriate, any strategy for cystocele correction must repair the causative apical and lateral fascial tears, with either permanent suture or a mesh bolster. However, a postal survey of practice patterns among British gynaecologists showed that $77 \%$ of respondents still manage cystoceles by anterior colporrhaphy [7]. The same survey was later mailed to Australian and New Zealand gynaecologists, where $54 \%$ of respondents also nominated anterior colporrhaphy as their preferred treatment for cystocele, compared with $12 \%$ using paravaginal repair (E. Seman, personal communication; October 2007). However, compared to general obstetrician gynaecologists, certified urogynaecologists and surgeons with a special interest in pelvic floor disorders were less likely to repair cystocele by anterior colporrhaphy.

This study was undertaken to define the benefits specifically attributable to site-specific cystocele repair. Our research hypothesis was that strengthening the apical supports and suturing the avulsed pubocervical fascia back onto the arcus tendineus fascia pelvis (ATFP) would provide a durable cystocele repair, irrespective of whether the repair was done transabdominally or trans-vaginally.

\section{Methods}

The study population comprised a sub-sample of 111 women, drawn from an overall population of 275 sitespecific prolapse repairs, done personally between February 1997 and August 2007 (Fig. 1). Analysis is based upon a retrospective review of standard clinical data, systematically collected as part of routine clinical practice and recorded in the first author's office charts. Subjects were recruited from three sources: routine gynaecological referrals from general practitioners in the South East suburbs of Sydney, where the private practice is located (21 women); tertiary pelvic floor referrals from distant metropolitan suburbs of Sydney (33 women) and regional Australian cities (19 women); and referrals seen in a rural outpatient clinic in north western New South Wales, established under the Federally
Fig. 1 The value of site-specific repair using just the native tissues was explored in 111 women who had either vaginal or abdominal paravaginal repair. The study sample was drawn from a population of 275 women who had site-specific prolapse repairs over an 11-year period (from 1997 to 2007).

In a companion article, biomaterial usage was subsequently evaluated by comparing 108 women augmented vaginal paravaginal repairs VPVRs (90 women having a remodelling biomesh and 18 women having an Amid class I polypropylene mesh) with the 59 native tissue vaginal operations described in this paper

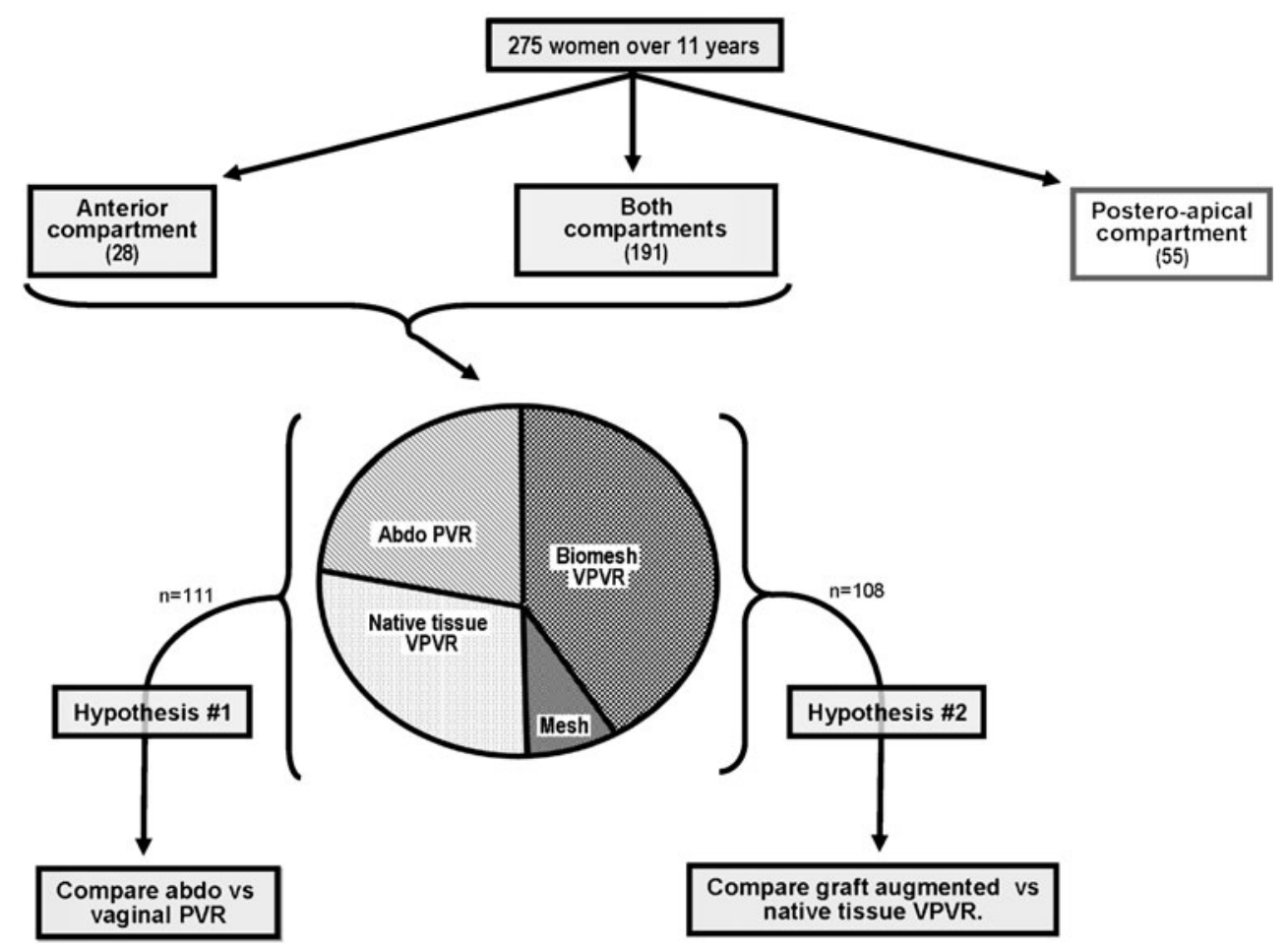


funded Medical Specialist Outreach Assistance Program (38 women). As a group, these women had complex anatomic and functional problems: $89 \%$ had severe urinary incontinence, voiding difficulty, dyspareunia, obstructive defaecation or faecal incontinence (the remainder had only drag and bulge discomfort); $78 \%$ had prior or concurrent hysterectomy; $70 \%$ had prolapse beyond the hymenal ring, $81 \%$ required multicompartment prolapse repair, and $46 \%$ had either prior operative failure or a documented collagen weakness. Data collection was regarded as a quality assurance project, and therefore exempted from Human Research Ethics Committee review.

Inclusion criteria were the presence of a symptomatic displacement cystocele, treated by re-suturing the torn native tissues. The sole exclusion criterion was the use of a tissue augmentation material; repairs using synthetic or biological mesh implants are reported in a separate article (Fig. 1). Of these 111 native tissue paravaginal repairs, 52 were done by the abdominal and 59 by the vaginal route. The primary surgical philosophy was to "leave the entire tract intact" at the index operation, meaning that incipient support laxity in adjacent compartments and overt multicompartment prolapse were repaired with the same vigour [8]. As such, 90 women had concomitant repair of apical support defects (either overt or subclinical); the other 21 women needed only cystocele repair. First follow up exam was at 6 months, to assess treatment reliability (i.e., whether paravaginal repair of cystocoele had been technically successful); subsequent visits were done at approximately annual intervals, to assess treatment durability (i.e., whether the initially successful repairs held up over time). Mean follow-up time was 72 months (range 22-141 months). Treatment allocation was by surgeon assignment, with patient input as to preferred route of surgery. Abdominal paravaginal repair (APVR) was favoured in women with a lifestyle involving heavy physical exertion, and in those requiring laparotomy to manage any co-morbidity. Such women tended to be premenopausal. Vaginal paravaginal repair (VPVR) was favoured in all other women. These individuals tended to be postmenopausal, and any obstetric fascial damage in adjacent compartments was more likely to have progressed over time (from incipient support laxity to overt multicompartment prolapse).

Primary measures of outcome were: same-site (anterior segment) prolapse recurrence, time to failure and the occurrence of a significant surgical complication. Secondary measure of outcome were different site (postero-apical segment) anatomic recurrence and persistent or de novo pelvic organ dysfunction; this data will be presented in subsequent articles. Data collection for this study began before the POPQ staging had become widely established, so we continued to gauge anatomic outcome by the Baden Walker "halfway" system [8]. Objective anatomic success was defined as either ideal support (Baden-Walker stage 0) or mild laxity (Baden-Walker stage 1). Functional success was determined from answers to a symptom inventory taken at presentation and follow up.

Abdominal paravaginal repair was done through a Pfannenstiel incision, using a Bookwalter self-retaining retractor for adequate exposure. First priority upon entering the paravesical space was to carefully examine the area near the superior pubic ramus, to look for accessory obturator vessels. Laceration of a high volume collateral circulation between the internal (via the main obturator vessels) and external iliac systems (via the inferior epigastrics) can produce catastrophic bleeding [9, 10]. Because aberrant obturator vessels seldom course anterior to the obturator notch, dissection to search for paravaginal defects was begun near the symphasis pubis. Mobilisation of obscuring fibro-fatty tissue was hinged on an imaginary fulcrum, centred just lateral to the obturator notch. Tears avulsing the pubocervical fascia from the ATFP were repaired by reanchoring the detached anterior vaginal suspensory hammock to the pelvic girdle with four or five pairs of interrupted permanent sutures. Placing these anchoring sutures can be awkward, as the ATFP is typically about 20-25 cm deep to the skin incision, and closely related to the ascending segment of ureter $[11,12]$. In addition to the repair of medial paravaginal defects, a search was made for any weakness lateral to the ATFP - arising through avulsion of the ATFP and obturator fascia from periosteum of superior pubic ramus and obturator internus muscle. Native tissue vaginal paravaginal repair is a simpler procedure. The operation begins by sharply incising the vaginal epithelium, thus exposing the superficial surface of the pubocervical septum. The avulsed lateral and apical edges of the central suspensory hammock are then mobilised, for re-attachment to the pelvic sidewall. This was done using a "three point" closure, wherein each monofilament permanent suture incorporated the ATFP, the avulsed edge of the pubocervical fascia and the muscularis of the lateral vaginal wall [13].

Statistical analysis examined both short-term (i.e., 6 month) reliability and long-term durability of cystocele repair (i.e., time to failure). Whether or not an effective mechanical repair had been achieved in the first instance was inferred from anatomic findings at the 6-month postoperative visit, using chi-square test of independence and logistic regression analysis [14]. The latter allows for multivariate analyses to control for possible confounding variables. Long-term anatomical durability of an initially successfully site-specific cystocele repair was first examined with the Kaplan-Meier survival curves and log rank test, then further evaluated using the Cox proportional hazards model [15]. The impact of potential confounding variables was also investigated. 


\section{Results}

Group comparison of demographic and potentially confounding variables revealed mean age of the APVR cases to be 10.2 years younger, reflecting the more common need for an abdominal incision in menstruating women (Table 1). No statistical difference was seen in the distribution of other potentially confounding variables, such as BMI $>25 \mathrm{Kg} / \mathrm{M}^{2}$, multi-compartment prolapse, prior or concomitant hysterectomy, prior failed surgery, severe urinary incontinence or suspected collagen weakness.

Patient age $[16,17]$ and the need for multi-compartment prolapse repair $[1,2]$ have been perceived to be adverse prognostic factors. However, with respect to the restoration of normal anterior compartment anatomy at 6-month follow-up, neither covariate was an important confounder at logistic regression analyses. The $95 \%$ confidence intervals (CI) of odds ratios (OR) comparing VPVR to APVR were $0.818-9.243 ; p$ value $=0.102>0.05$ before adjusting and 0 . 651-8.176; $p$ value $=0.375>0.05$ after adjusting for potential confounding factors (Table 2). Both $95 \%$ CI of OR was very wide and included ' 1 ', implying that the route of paravaginal repair did not impact shortterm reliability. Nor were age or multi-compartment prolapse shown to be effect modifiers for short-term repair outcome.

However, the Kaplan-Meier survival analysis curves for APVR and VPVR diverged steadily over time (Fig. 2). APVR conferred a greater chance of remaining prolapsefree in the long term [46 out of $52(88.5 \%)$ versus 41 out of $59(69.5 \%)]$. The interaction between age and long-term treatment outcome were examined in the Cox model. VPVR hazards ratio confidence intervals were 1.065-

Table 1 Group comparison of baseline demographics and potentially confounding factors

\begin{tabular}{llll}
\hline $\begin{array}{l}\text { Baseline } \\
\text { demographics } \\
\text { and potential } \\
\text { confounders }\end{array}$ & $\begin{array}{l}\text { Abdominal } \\
\text { paravaginal } \\
\text { repair }\end{array}$ & $\begin{array}{l}\text { Vaginal } \\
\text { paravaginal } \\
\text { repair }\end{array}$ & $P$ value \\
\hline $\begin{array}{l}\text { Mean age } \\
\begin{array}{l}\text { Overt prolapse in a } \\
\text { second vaginal }\end{array}\end{array}$ & $87 \%$ & 61.9 years & $<0.0001^{\mathrm{a}}$ \\
$\begin{array}{c}\text { compartment } \\
\begin{array}{c}\text { Concomitant } \\
\text { hysterectomy }\end{array}\end{array}$ & $37 \%$ & $76 \%$ & $0.168(\mathrm{~ns})$ \\
$\begin{array}{l}\text { Prior hysterectomy } \\
\text { Prior failed surgery }\end{array}$ & $40 \%$ & $24 \%$ & $0.141(\mathrm{~ns})$ \\
$\begin{array}{c}\text { Suspected collagen } \\
\text { weakness }\end{array}$ & $21 \%$ & $44 \%$ & $0.695(\mathrm{~ns})$ \\
$\begin{array}{c}\text { Severe incontinence } \\
\text { BMI>25 Kg/M }\end{array}$ & $48 \%$ & $34 \%$ & $0.893(\mathrm{~ns})$ \\
\hline
\end{tabular}

${ }^{\mathrm{a}}$ Significant $2.683(p$ value $=0.026<0.05)$ before adjusting, and 1.029 2.708 ( $p$ value $=0.038<0.05$ ) after adjusting for potential confounders (Table 3). Neither age nor multi-compartment prolapse were identified as effect modifiers ( $p$ values $>0.05$ ). Although the interactions between potential confounders and the repair method appeared minimal, the ability of the Cox regression analysis to detect confounding within our data was limited by small sample size (111), high censoring proportion (78\%) and the fact that most premenopausal women received APVR while most postmenopausal women received VPVR. Another possible explanation for the lack of confounding effect by these widely recognised risk factors lies with the surgical philosophy to "leave the entire tract intact" at the index operation. Perhaps for this reason, re-enforcing apical support at cystocele repair neither increased nor decreased cystocele recurrence rates within this study (Table 2).

With respect to symptom control, both abdominal and vaginal paravaginal repair provided comparable relief of bulge discomfort [40 of $45(88.9 \%)$ versus 45 of 55 $(81.8 \%) ; \chi^{2}=0.92, p$ value $\left.=0.32>0.05\right]$. Of the 111 women who had native tissue repairs, 43 of $52(82.7 \%)$ women having APVR remained or were rendered dry, compared with 41 of $59(69.5 \%)$ after VPVR $\left[\chi^{2}=2.62, p=0.106>\right.$ $0.05]$. Nine women with persisting stress urinary incontinence opted for bulking injection or mid-urethral sling placement as a follow-up procedure. Of 69 women with overactive bladder complaints, 20 of $32(62.5 \%)$ APVR women had resolution of their urge urinary incontinence, compared with 16 of $37(43.2 \%)$ after VPVR $\left[\chi^{2}=2.55, p\right.$ value $=0.11>0.05]$. This difference was not statistically significant, perhaps reflecting the limited number of patients studied. A possible explanation for the observed improvement in urge urinary incontinence is that some of the overactive bladder activity may have been due to urinary reflux into the proximal urethra, a problem that was potentially controllable by reducing vesical neck hypermobility. Finally, of 14 women with pre-existent dyspareunia, sexual pain was resolved in five of six women having APVR and in three of eight having VPVR; however, two individuals in each group developed de novo dyspareunia. Hence, there was a $28 \%$ decrease in the overall rate of intercourse pain (from 14 to 10 complainants).

Over the course of 10-year follow-up, $62.5 \%$ of failures were apparent at the 6-month visit; the remaining $37.5 \%$ occurred in the succeeding 32 months. The flattening of the Kaplan-Meier curves by 38 months confirms that paravaginal repair (from either direction) can be curative of cystocele. Four $(3.6 \%)$ significant peri-operative complications occurred: a unilateral obturator nerve avulsion requiring re-suture, a ureteric occlusion requiring immediate psoas hitch re-implantation and an extensive bladder laceration requiring an extra 10 days hospitalisation in the 
Table 2 Potential confounding factors - logistic regression and Cox proportional hazard analysis

Factor $95 \%$ CI of odds ratio $\quad p$ value $\quad$ Significant

Logistic regression on short-term outcome

Before adjusting for confounders

VPVR vs. APVR $\quad 0.818-9.243$

0.651-8.176

$0.102>0.05$

No

After adjusting for confounders

VPVR vs. APVR

$0.357>0.05$

No

Cox modelling on long-term outcome

Before adjusting for confounders

VPVR vs. APVR

1.065-2.683

$0.026<0.05$

Yes

After adjusting for confounders

VPVR vs. APVR

1.029-2.708

$0.038<0.05$

Yes

Estimated effects of repair method before and after adjusting for potential confounding factors (age and multi-compartment prolapse)

APVR group and a unilateral paravesical space haematoma that broke down the initial repair in the VPVR group. None of these events relate specifically to paravaginal repair. While there was no statistical difference in complication rates within this sample $(5.8 \%$ vs. $1.7 \%)$, it is a surgical reality that abdominal paravaginal repair is more invasive for the patient and more complex for the surgeon.

\section{Discussion}

Both vaginal and abdominal paravaginal repairs were efficacious. No anatomic failure occurred after 38 months, indicating that site-specific repair by either route has genuine curative potential. APVR appeared slightly more durable [46 out of $52(88.5 \%)$ versus 41 out of $59(69.5 \%)$; logrank $=5.472, p$ value $=0.0193<0.05]$. However, the possibility that the $19 \%$ advantage for APVR represents an undetected confounding effect due to selection bias is not entirely excluded. From a technical perspective, there is a plausible explanation for the observed difference in longterm success rates-namely, that suspensory sutures are placed into the lateral vaginal wall at APVR, rather than

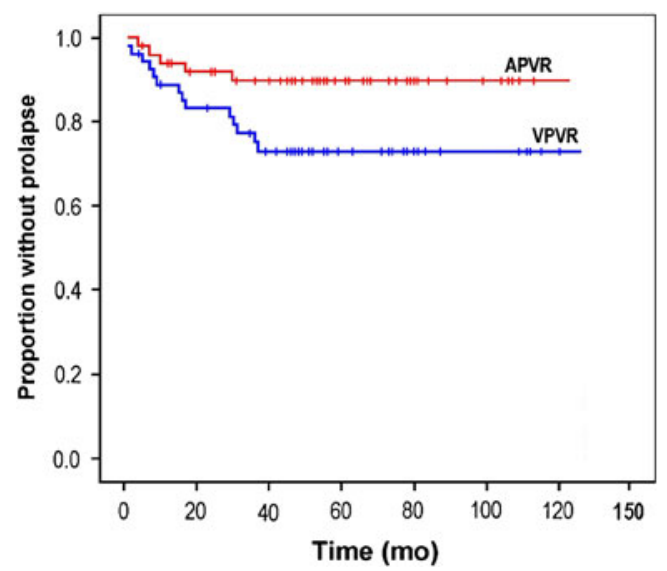

Fig. 2 Kaplan-Meier survival curves, showing good durability for both methods of paravaginal repair during follow up of up to 10 years. APVR was $19 \%$ more effective than VPVR over the long term having to search for the quite elusive torn edges of the central fascial hammock at VPVR. Trans-abdominal repairs also close the 'site-specific' defect over a shorter distance (thus creating less suture-line tension). The 69.5\% longterm success rate for native tissue VPVR is lower than reported in other clinical series [13, 18-20] (Table 4), reflecting our stringent definition of failure and our long duration of follow-up (with the last recurrence occurring more than 3 years after surgery). In fact, the main strength of this study is that 59 transvaginal and 52 transabdominal native tissue repairs were followed for at least 6 years beyond the complete flattening of the Kaplan-Meier curve (i.e., a reasonable surrogate for lasting cure). Data on the reliability and durability of native tissue cystocele repairs are pertinent to the decision on what role trocar-driven mesh kits should play in prolapse surgery. But, as with all retrospective studies, there were inherent methodological limitations in this paper. The primary question of interest was to examine whether biomechanically equivalent surgery done from different directions had similar long-term success rates. Our basic analysis therefore needed to compare 10-year outcomes for abdominal and vaginal paravaginal repair of cystocele. However, these were not random samples. Women having APVR had a 10.2 years younger mean age, while the VPVR group had a $23 \%$ higher frequency of multi-compartment prolapse. The ability of Cox modelling or logistic regression analyses to detect confounding because of age difference or the need for multi-compartment repair is compromised by an unbalanced distribution of these factors across treatment groups. Future studies using random treatment assignment would be needed to resolve this uncertainty. Generalizability of this study may also be limited by fact that all cases were operated upon by a single surgeon. Despite these limitations, we believe the observed differences between APVR and VPVR to be both biologically plausible and reproducible.

This paper has two important implications for clinicians. While the $88.5 \%$ long-term success rate from above was pleasing, APVR has a morbidity potential comparable to 
Table 3 Potential confounding factors - contingency analysis on concomitant apical surgery
Log rank test analysis of concomitant apical compartment support vs. cystocele recurrence by repair group (APVR vs. VPVR)

\begin{tabular}{|c|c|c|c|}
\hline & \multicolumn{2}{|c|}{ Long-term outcome } & \multirow[t]{2}{*}{ Total } \\
\hline & Success & Failure & \\
\hline \multicolumn{4}{|l|}{ Abdominal paravaginal repair } \\
\hline No additional apical support needed & $6(86 \%)$ & 1 & 7 \\
\hline Concomitant apical support by uterosacral ligament culdoplasty & $22(92 \%)$ & 2 & 24 \\
\hline $\begin{array}{l}\text { Concomitant apical support by open sacrocolpopexy, using } \\
\text { polypropylene mesh }\end{array}$ & $18(86 \%)$ & 3 & 21 \\
\hline Total & 46 & 6 & 52 \\
\hline \multicolumn{4}{|l|}{ Four year log rank $\chi^{2}=0.419 ; p$ value $=0.811(\gg>0.05)$} \\
\hline \multicolumn{4}{|l|}{ Vaginal paravaginal repair } \\
\hline No additional apical support needed & $10(71 \%)$ & 4 & 14 \\
\hline Concomitant apical support by uterosacral ligament culdoplasty & $10(71 \%)$ & 4 & 14 \\
\hline Concomitant apical support by unilateral sacrospinous fixation & $21(70 \%)$ & 10 & 31 \\
\hline Total & 41 & 18 & 59 \\
\hline Four year $\log$ rank $\chi^{2}=0.534 ; p$ value $=0.766(>>0.05)$ & & & \\
\hline
\end{tabular}

pelvic lymphadenectomy. Our view remains that APVR is too invasive and too difficult to ever become the "gold standard" operation for displacement cysto-urethrocele. In contrast, VPVR is a distinctly easier operation with a reduced capacity for major morbidity. The second clinical issue relates to the value of site-specific repair. Traditional anterior colporrhaphy is a quicker and simpler operation, but does not address the actual sites of anatomic damage. Nonetheless, cystocele plication proves durable in a proportion of patients, presumably through the formation of a non-specific scar plate beneath the vesical neck and bladder [21]. Thus, to properly quantify the reparative value of site-specific repair, one must first account for whatever benefit that postoperative fibrosis may have conferred. Long-term efficacy of anterior colporrhaphy was estimated from the literature and from the observed outcomes of prior cystocele repairs in our study population. Despite cystocele repair being among the commonest operations in gynae- cology [22], objective success rates and long-term repair durability are poorly described in the medical literature [23]. Recurrence rates from case series have generally been reported in the $0-30 \%$ range; however, more rigorous assessment in two randomised control trials reported much higher rates of objective anatomic failure. Sand [24] observed anatomic failure in 30 of $70(43 \%)$ nonaugmented anterior colporrhaphies at 12 months. In comparing three different methods of anterior repair (standard suture-only plication, ultralateral suture-only plication and standard plication augmented by a Vicryl mesh), Weber [25] found no difference between groups. Although each method provided reasonable symptomatic control of bulge discomfort, aggregate objective failure rate climbed to 51 of 83 operations $(61.4 \%)$ by 2 years. Moreover, the tails of the Kaplan-Meier curves were still falling at study conclusion (reaching $\sim 35 \%$ at 27 months). Projecting Weber's $\sim 35 \%$ success rate forwards would

Table 4 Summary of other similar studies reported previously

\begin{tabular}{|c|c|c|c|}
\hline \multirow[t]{2}{*}{ Author } & \multicolumn{2}{|c|}{ Same site anatomic failure } & \multirow[t]{2}{*}{ Major complication rate $(\%)$} \\
\hline & Failure rate $(\%)$ & Mean follow-up (months) & \\
\hline Shull [20] & $4 / 62(7.1)$ & 19 & $7 / 62(11.3)$ \\
\hline Mallipeddi [15] & $4 / 45(17.1)$ & 20 & $6 / 45(8.9)$ \\
\hline Young [21] & $24 / 100(24.0)$ & 11 & $24 / 100(24.0)$ \\
\hline Viana [22] & $5 / 66(7.6)$ & 12 & $0 / 66(0.0)$ \\
\hline Reid [29] & $18 / 59(30.5)$ & 59 & $1 / 59(1.7)$ \\
\hline Total & $57 / 332(17.2)$ & 23 & $38 / 332(11.4)$ \\
\hline
\end{tabular}

Same-site anatomic failure rates, mean lengths of follow-up and major complication rates in five clinical series reporting on native tissue vaginal paravaginal repair. Failure rate in this series is substantially higher than quoted by Shull [18], Mallipeddi [13], or Viana [20]. This difference probably relates to our stringent definition of failure and our long duration of follow-up (with recurrences occurring as long as 38 months postsurgery) 
overestimate the true durability of anterior colporrhaphy. A different perspective is provided by the 93 women in this database who had a previous anterior-posterior colporrhaphy. Of these women, $8 \%$ manifested only anterior segment failure and another $78 \%$ had multi-site failure. However, in the $14 \%$ with just posterior segment failure, prior anterior repairs had proven durable. Given that all repaired compartments no doubt remained well supported in some women, projecting $14 \%$ as the long-term success rate of anterior plication repairs would be an underestimate.

Despite the obvious limitations of these calculations, the long-term durability of anterior colporrhaphy probably lies somewhere between the $\sim 35 \%$ projection from Weber's 2 year trial and the $\sim 14 \%$ projection from prior colporrhaphy failures in this database. There are no further data to help narrow this $21 \%$ range. Given that we almost never combined VPVR with concomitant tissue imbrication, it is unlikely that postoperative cicatrization contributed significantly to cystocele support in this study. Bump [26] and Kohli [27] reported substantially higher failure rates from plication plus needle suspension than from plication alone, due to the deleterious effect of not repairing the iatrogenic paravaginal defects in the former group. Quantifying the benefit attributable to sitespecific repair needs the application of this $14-35 \%$ corrective factor. The $69.5 \%$ ten-year durability of native tissue VPVR in this study confirmed the first part of the research hypothesis. Site-specific repair of the predicted fascial avulsion points within anterior compartment prolapse does indeed deliver additional long-term success, over and above whatever benefits is achieved from creation of a nonspecific suburethral scar plate (Fig. 3).

From a research perspective, a distinction should be made between operative failure due to inadequate tissue approximation versus operative failure due to disordered healing. Wound repair involves two different series of events [28, 29]. The early healing phase is concerned principally with inward migration and subsequent proliferation of inflammatory cells and fibroblasts. This culminates in the deposition of an extracellular matrix with relatively large amounts of soft immature collagen. The scar maturation phase involves transformation of this monomeric immature (type III) collagen into an organised array of highly cross-linked triple helix polymers (type I collagen) [29]. Broadly speaking, 6 months is something of a watershed between early healing and scar maturation. To help differentiate mechanical from biochemical failure, our initial postoperative examination was done at about this time. Restoration of normal anatomy at the 6-month visit offers reasonable assurance that a mechanically sound site-specific repair had been accomplished. Conversely, late failure after a normal 6-month exam suggests the fault lies with fibroblast biochemistry or matrix remodelling. In this study, 10 of the 24 recurrent cystoceles were apparent at the 6-month follow up examination, implicating technical

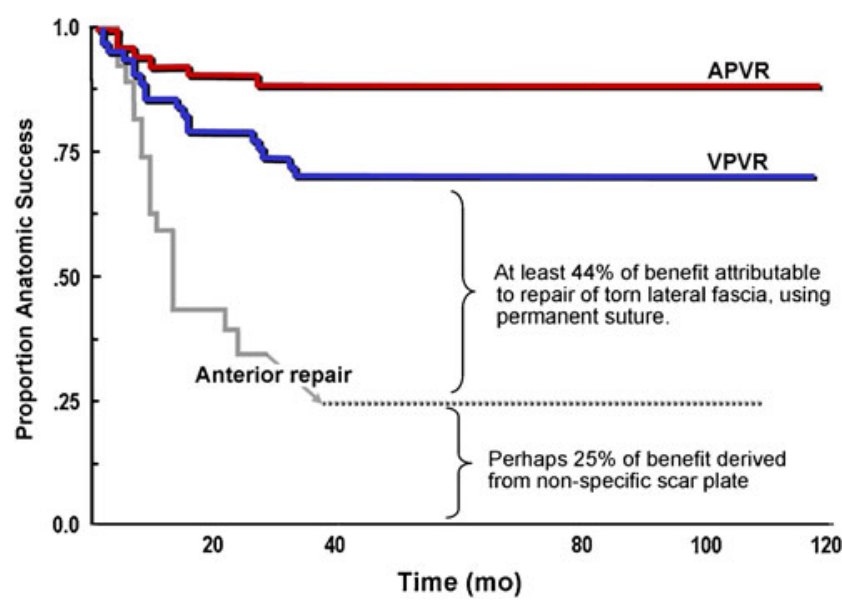

Fig. 3 Kaplan-Meier survival curves, with an approximation of the possible reparative benefits of non-specific scar formation secondary to dissection of the anterior compartment. Applying this corrective factor, there was an additional reparative benefit attributable to sitespecific re-suture of the predicted fascial avulsions. The VPVR survival curve perhaps represents the ceiling of what is attainable through simple re-suture of native tissues. Analogy with hernia repair suggests that further improvement in anatomic outcome will require strategies to limit suture line tension and overcome collagen weakness in the adjacent connective tissues [30]

factors as the likely cause of failure. This observation is in keeping with surgical experience. The most difficult part of a "suture only" paravaginal repair (by either surgical route) often lies in locating the edges of the fascial defect that initiated the support failure. Direct obstetric trauma can also have an almost explosive effect on the anterior suspensory hammock, creating actual tissue deficits rather than simple fascial lacerations. Mobilising the avulsed central trapezoid back to the pelvic sidewall supports without undue wound tension is difficult, especially in women who have had a central diamond of vaginal mucosa excised at a prior anterior colporrhaphy. But the observation that early success rates were independent of route of repair suggests that APVR and VPVR were equally effective at re-uniting the torn fascial edges. In contrast, the higher rate of late cystocele recurrence after VPVR points to the importance of disordered collagen homeostasis in chronic prolapse. The description of Young et al. [19] of recurrent midline cystocele formation several months after satisfactory lateral repair of the defects suggests that sustained lateral tension may overwhelm fatigued collagen within the central hammock.

The use of tissue augmentation materials might therefore counteract both technical and biochemical failure mechanisms.

\section{Conclusions}

The pathogenesis of cystocele generally begins with sitespecific fascial tears at top and side, as the vaginal 
suspensory hammock is avulsed from the pelvic sidewall during vaginal delivery. The elastic tissues of young women often camouflage this obstetric damage, but accrued weakness may evolve into symptomatic prolapse as host tissues weaken over time. Optimal cystocele repair seems to require two things: that the specific fascial defects (not the secondary bulges) be repaired without tension, and (preferably) that degenerative connective tissue bordering these fascial tears be rejuvenated with augmentation material $[29$, $30]$. With respect to the first premise, accurate reattachment of torn native tissues using interrupted permanent sutures can be genuinely curative of cystocele, as evidenced by the absolute plateauing of the Kaplan-Meier curves at 38 months. At least $35-54 \%$ of the long-term success was attributable to site-specific re-suturing of the torn native tissues, rather than to formation of a nonspecific scar plate. Whether a $69.5 \%$ success rate from native tissue VPVR truly justifies the additional surgical effort involved in paravaginal repair, instead of anterior colporrhaphy (as a palliative treatment) or mesh augmented PVR (as a more robust curative procedure) is debatable.

Acknowledgements We acknowledge Ms. Christine Morton, BA Rural Sc (Hons) from School of Rural Medicine, Armidale for additional statistical support.

\section{Conflicts of interest None.}

Funding No external funding was used.

Open Access This article is distributed under the terms of the Creative Commons Attribution Noncommercial License which permits any noncommercial use, distribution, and reproduction in any medium, provided the original author(s) and source are credited.

\section{References}

1. Summers A, Winkel LA, Hussain HK, Delancey JO (2006) The relationship between anterior and apical compartment support. Am J Obstet Gynecol 194:1438-1443

2. Rooney K, Kenton K, Mueller ER, FitzGerald MP, Brubaker L (2006) Advanced anterior vaginal wall prolapse is highly correlated with apical prolapse. Am J Obstet Gynecol 95:1837-1840

3. DeLancey JO (1994) Structural support of the urethra as it relates to stress urinary incontinence: the hammock hypothesis. Am J Obstet Gynecol 170:1713-1720

4. Rogers RM (2007) Operative anatomy for the vaginal surgeon. In: Kovac SR, Zimmerman CW (eds) Advances in vaginal reconstructive surgery. Wolters Kluwer/Lipppincott Williams \& Wilkins, Philadelphia, pp 3-20

5. Tegerstedt G, Miedel A, Maehle-Schmidt M, Nyren O, Hammarstrom M (2006) Obstetric risk factors for symptomatic prolapse: a population-based approach. Am J Obstet Gynecol 194:75-81

6. Zimmerman CW (2007) Posterior vaginal reconstruction with bilateral uterosacral colpopexy. In: Kovac SR, Zimmerman CW (eds) Advances in reconstructive vaginal surgery. Wolters Kluwer/ Lipppincott Williams \& Wilkins, Philadelphia

7. Jha S, Moran PA (2007) National survey on the management of prolapse in the UK. Neurourol Urodyn 26:325-331

8. Baden WF, Walker T (1992) Surgical repair of vaginal defects. JB Lippincott, Philadelphia

9. Darmanis S, Lewis A, Mansoor A, Bircher M (2007) Corona mortis: an anatomical study with clinical implications in approaches to the pelvis and acetabulum. Clin Anat 20:433-439

10. Drewes PG, Marinis SI, Schaffer JI, Boreham MK, Corton MM (2005) Vascular anatomy over the superior pubic rami in female cadavers. Am J Obstet Gynecol 193:2165-2168

11. Barksdale PA, Brody SP, Garely AD, Elkins TE, Nolan TE, Gasser RF (1997) Surgical landmarks of the ureter in the cadaveric female pelvis. Clin Anat 10:324-327

12. Rahn DD, Bleich AT, Wai CY, Roshanravan SM, Wieslander CK, Schaffer JI, Corton MM (2007) Anatomic relationships of the distal third of the pelvic ureter, trigone, and urethra in unembalmed female cadavers. Am J Obstet Gynecol 197(668):e1-e4

13. Mallipeddi PK, Steele AC, Kohli N, Karram MM (2001) Anatomic and functional outcome of vaginal paravaginal repair in the correction of anterior vaginal wall prolapse. Int Urogynecol J 12:83-88

14. Agresti A (2002) Categorical data analysis, 2nd edn. Wiley, Hoboken

15. Collett D (1994) Modelling survival data in medical research. Chapman \& Hall Publishing, New York

16. Whiteside JL, Weber AM, Meyn LA, Walters MD (2004) Risk factors for prolapse recurrence after vaginal repair. Am J Obstet Gynecol 191:1533-1538

17. Diez-Itza I, Aizpitarte I, Becerro A (2007) Risk factors for the recurrence of pelvic organ prolapse after vaginal surgery: a review at 5 years after surgery. Int Urogynecol J 18:1317-1324

18. Shull BL, Benn SJ, Kuehl TJ (1994) Surgical management of prolapse of the anterior vaginal segment: an analysis of support defects, operative morbidity, and anatomic outcome. Am J Obstet Gynecol 171:1429-1436

19. Young SB, Daman JJ, Bony LG (2001) Vaginal paravaginal repair: one-year outcomes. Am J Obstet Gynecol 185:1360-1366

20. Viana R, Colaco J, Vieira A, Goncalves V, Retto H (2006) Cystocele-vaginal approach to repairing paravaginal fascial defects. Int Urogynecol J 17:621-623

21. Bergman A, Elia G (1995) Three surgical procedures for genuine stress incontinence: five-year follow-up of a prospective randomized study. Am J Obstet Gynecol 173:66-71

22. Cardozo L (1995) Prolapse. In: Whitfield CR (ed) Dewhurst's textbook of obstetrics and gynaecology for postgraduates. Blackwell Science, Oxford, pp 642-652

23. Jelovsek JE, Maher C, Barber MD (2007) Pelvic organ prolapse. Lancet 369:1027-1038

24. Sand PK, Koduri S, Lobel RW, Winkler HA, Tomezsko J, Culligan PJ, Goldberg R (2001) Prospective randomized trial of polyglactin 910 mesh to prevent recurrence of cystoceles and rectoceles. Am J Obstet Gynecol 184:1357-1362

25. Weber AM, Walters MD, Piedmonte MR, Ballard LA (2001) Anterior colporrhaphy: a randomized trial of three surgical techniques. Am J Obstet Gynecol 185:1299-1304

26. Bump RC, Hurt WG, Theofrastous JP, Addison WA, Fantl JA, Wyman JF, McClish DK (1996) Randomized prospective comparison of needle colposuspension versus endopelvic fascia plication for potential stress incontinence prophylaxis in women undergoing vaginal reconstruction for stage III or IV pelvic organ prolapse. The Continence Program for Women Research Group. Am J Obstet Gynecol 175:326-333

27. Kohli N, Sze EH, Roat TW, Karram MM (1996) Incidence of recurrent cystocele after anterior colporrhaphy with and without 
concomitant transvaginal needle suspension. Am J Obstet Gynecol 175:1476-1480

28. Franz MG (2006) The biology of hernias and the abdominal wall. Hernia 10:462-471

29. Reid RI (2011) A comparative analysis of biomaterials currently used in pelvic reconstructive surgery. In: Von Theobald P,
Zimmerman CW, Davila W (eds) Vaginal prolapse surgery: new techniques. Springer, Guildford

30. Reid RI (2011) Hernia principles: what general surgeons can teach us about prolapse repair? In: Von Theobald P, Zimmerman CW, Davila W (eds) Vaginal prolapse surgery: new techniques. Springer, Guildford 